\title{
Ayurvedic approach to alcohol withdrawal syndrome
}

Volume 7 Issue 3 - 2017

\author{
Jithesh Madhavan \\ PG Department of Ayurvedic Psychiatry,VPSV Ayurevda \\ College, India
}

\section{Editorial}

The healthy intake of alcohol was a part of the cultural and social life it is mentioned as the ultimate among the drugs causing soumanasya ie. a pleasant state of mind. It was used as a medicinal preparation in the form of arishtas by the Ayurvedic community for the effective management of several clinical conditions. The rapid absorption of the alcohol and its preparations are positively used in clinical medicine, by the ancient scholars as these are having brisk action. The unhealthy use of alcohol is contributing to many a physical, psychological and social problem and is contributing to approximately $4 \%$ of the deaths worldwide. $1 / 5$ th of the psychiatric patients have the abuse of alcohol in association.

Alcohol withdrawal syndrome is a set of symptoms on reduction / stoppage of consumption after prolonged use, 6 to 24hours after the drink that lasts upto more than 1week due to hyper excitable response of Central Nervous System to lack of Alcohol, which may be mild sleep disturbance/ anxiety to life threatening situations like delirium. The stages from I to IV include tremulousness, hallucination, seizures and delirium tremens. The severity of symptoms depends on degree of alcohol intake, duration of intake, general health condition, age and prakrithi of the individual etc.

The management is diverse as there are multiple perspectives in the pathogenesis of an alcoholic disorder. The three relevant steps are intervention, detoxification and rehabilitation. The modern medical management seldom works as expected in this group of affected, the management being quite conditional as per the available studies.

The excessive intake of unwholesome alcohol leads to madatyaya as explained in Ayurvedic classics. It leads to both the physical and psychological symptoms. Most of the manifestation varies as per the aggravated dosha, as the alcohol alters all the three doshas, eventhough in general, the madatyaya is considered as Vathapittaja in nature. Eg in Vathika madatyaya, the main symptoms are hidhma, swasa, sirah kampa, parswasoola, nidranasa and pralaapa. The madya alters or depletes the ojus and its functions as it is entirely opposite in quality to the ojus. The chronicity leads to other complications such as neuropathy, hepatopathy etc.

In chronic conditions as well as excess alteration of the doshas, the Sodhana therapy is advised. The selection of Sodhana is based on the dosha status of the presentation. We have to opt for Vamana when the Kaphaja features such as praseka, Aruchi, agnimandya etc. are predominant. Virechana is the option if the individual presents with daha, trishna, brama etc. The condition which is much more Vathika in nature with soola, adhmana, angamarda etc. responds to snehapana itself rather than sodhana. This is followed by vasthikarma, the selection of the combination is again based on Doshas. Ksheeravasthi is the mostly used one with the selection of the drugs, as per the status of the doshas.

This is followed by nasya, mostly brimhana in nature using drugs such as ksheerabala taila, grithamanda, dhanwantaram taila etc. In the initial stage of the management, use of nasya seems very much effective in the management of sleep related problems and also withdrawal hallucinations. Then the moordhni tailas or applications on the head are being done which includes sirodhara with medicated ksheera or taila, sirolepa, siropichu and even sirovasthi with appropriate medicines, as per the condition.

This is followed by the use of rasayanas. Here combinations such as mahakalyanaka gritha, chyavanaprasha, narasimha rasayana and individual drugs such as sankapushpi, brahmi, vacha as rasayanas need special mention in its use. The individuals are advised to practice selected yogasanas and pranayama techniques along with the experts. They will be provided with simple counseling twice a week. From the initial stage of the treatment itself, the patient is compelled to participate with family members, in the Alcoholics Anonymous group held once a week.

Such a real team work, along with the selected specific medicines, if administered will be definitely a boon for those affected with alcohol withdrawal syndrome. The ancient medical science has dealt with this condition with utmost seriousness as explained. By analyzing the various combinations mentioned in various treatises and also conducting sufficient trials, the vast treasure of Ayurveda may be made useful for the affected mankind due to the unauthentic use of alcohol. The earlier intervention in this area prevents many of the alcoholics from a stage of developing, the resultant psychiatric conditions. There is expectation and great scope of development in this area of Ayurvedic Psychiatry if sufficient studies are proposed and conducted in the near future.

\section{Acknowledgments}

None. 


\section{Conflicts of interest}

Author declares there are no conflicts of interest.

\section{Funding}

None. 